\title{
SUPPLY CHAIN MANAGEMENT
}

Supply Chain Management-SCM (Gerenciamento da Cadeia de Suprimentos) tornou-se um tema fundamental na área de gestão de operações. Significativamente, o número de títulos lançados vem crescendo ano a ano. Como a área de estudo é ainda nova, as obras tendem a abordar o assunto de forma genérica. A expectativa é de que, nos próximos anos, ocorra uma espe- cialização, levando os autores a focar aspectos mais específicos. A lista a seguir, preparada pela professora Eliane Pereira Zamith Brito, do Curso de Mestrado em Administração de Empresas da Universidade Presbiteriana Mackenzie e Ph.D. pela Manchester University, permite ao leitor uma visão ampla e atualizada do tema.

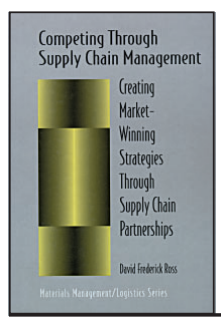

\section{COMPETING THROUGH SUPPLY CHAIN MANAGEMENT:} creating market-winning strategies through supply chain partnerships David Frederick Ross. Chicago : Kluwer Academic Publishers, 1997. 365 p. Esse livro aborda o SCM a partir de um enfoque estratégico. O autor apresenta $S C M$ como uma evolução da logística, sem perder de vista os aspectos de marketing. A leitura permite entender a diferença entre os conceitos de logística, SCM e administração dos canais de distribuição, que, segundo o autor, são usados como intercambiáveis, tanto na literatura como na prática. O potencial de ganhos advindos da adoção da filosofia e dos conceitos de $S C M$ é ressaltado.

\section{LOGISTICS AND SUPPLY CHAIN MANAGEMENT: strategies for reducing costs and improving services Martin Christopher. 2. ed. London : Prentice Hall, 1999. 294 p.

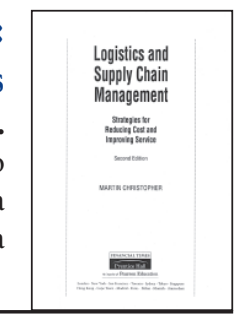
Trata-se de obra pioneira e que continua sendo muito utilizada. A leitura é fácil e, ao finalizá-la, ter-se-á adquirido um conhecimento básico dos aspectos tratados pelo SCM. O livro apresenta um enfoque que oscila entre logística e marketing, em função da experiência do autor nessas duas áreas, enfatizando os aspectos relacionados à primeira área de conhecimento. Para os iniciantes no estudo de cadeia de distribuição, é quase uma leitura obrigatória.

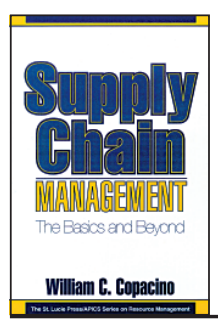

SUPPLY CHAIN MANAGEMENT: the basics and beyond

William C. Copacino. Boca Raton : St. Lucie Press \& APICS, 1997. 204 p.

Esse livro é uma coletânea de pequenos artigos de um renomado consultor das áreas de logística e SCM, anteriormente publicados no periódico Logistics Management. Apesar de compactos, os artigos permitem ao leitor uma visão de inúmeros aspectos envolvidos com o gerenciamento da cadeia de suprimentos. Os artigos não estão conectados entre si, tratando cada um de um aspecto diferente. $\mathrm{O}$ autor utiliza um enfoque prático, $\mathrm{o}$ que provê fluidez à leitura.

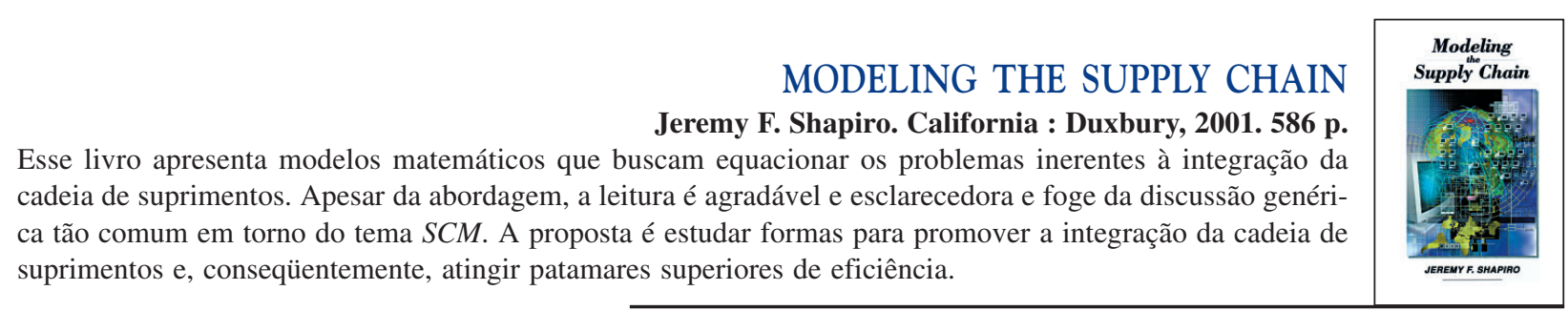

\section{SUPPLY CHAIN MANAGEMENT}

John T. Mentzer (Ed.). California : Sage, 2001. 512 p.

$\sin ^{2}$

Essa obra foi escrita por um grupo de oito pesquisadores. Os textos apresentam boa revisão bibliográfica e buscam elucidar a importância das principais áreas e funções operacionais das empresas na administração da cadeia de suprimentos. Como subsídio para a elaboração do livro, os autores entrevistaram diversos John T. Mentzer executivos. 